\title{
Химически осажденные пленки сульфида свинца, легированные кобальтом
}

\author{
(С) Л.Н. Маскаева ${ }^{1,2}$, Е.В. Мостовщикова ${ }^{3}$, В.Ф. Марков ${ }^{1,2}$, В.И. Воронин ${ }^{3}$, А.В. Поздин ${ }^{1}$, \\ И.О. Селянин ${ }^{4}$, А.И. Михайлова ${ }^{1}$ \\ ${ }^{1}$ Уральский фредеральный университет им. первого Президента России Б.Н. Ельцина, \\ 620002 Екатеринбург, Россия \\ ${ }^{2}$ Уральский институт ГПС МЧС России, \\ 620062 Екатеринбург, Россия \\ ${ }^{3}$ Институт фризики металлов им. М.Н. Михеева Уральского отделения Российской академии наук, \\ 620108 Екатеринбург, Россия \\ ${ }^{4}$ Институт химии твердого тела Уральского отделения Российской академии наук, \\ 620990 Екатеринбург, Россия \\ E-mail: larisamaskaeva@yandex.ru
}

Поступила в Редакцию 2 июля 2021 г.

В окончательной редакции 16 июля 2021 г.

Принята к публикации 16 июля 2021 г.

\begin{abstract}
В настоящей работе, являющейся продолжением исследований по легированию химически осажденных слоев $\mathrm{PbS}(\mathrm{I})$, обсуждается влияние ионов кобальта на их морфологические, структурные, оптические и фотоэлектрические свойства. Элементным энергодисперсионным анализом показано, что кобальт обнаруживается в пленках при концентрации его хлорида в реакционной смеси $\geq 0.04$ моль/л. Полученные пленки $\mathrm{PbS}(\mathrm{I}, \mathrm{Co})$ сохраняют кубическую $B 1$ структуру (пр. гр. $F m \overline{3} m)$. Установлена тенденция повышения ширины запрещенной зоны пленок $\mathrm{PbS}(\mathrm{I}, \mathrm{Co})$ от 0.57 до 0.75 эB с ростом в них содержания наночастиц с 1 до $\sim 8 \%$ при 1.5-часовом осаждении и от 0.57 до 0.68 эВ - с 13 до $\sim 28 \%$ при 3-часовом процессе. На концентрационной зависимости вольтовой чувствительности пленок $\mathrm{PbS}(\mathrm{I}, \mathrm{Co})$, осажденных в течение 1.5 ч, наблюдаются два максимума, соответствующие 1 и 4\% содержанию в них наночастиц. При трехчасовом процессе синтеза отмечено резкое снижение фотоответа с увеличением содержания частиц нанодиапазона до $\sim 13-28 \%$ в слоях $\mathrm{PbS}(\mathrm{I}, \mathrm{Co})$. Показано, что плотность фототока снижается с увеличением содержания наночастиц в пленках в ряду $\mathrm{PbS}(\mathrm{Co}) \rightarrow \mathrm{PbS} \rightarrow \mathrm{PbS}(\mathrm{I}, \mathrm{Co}) \rightarrow \mathrm{PbS}(\mathrm{I})$.
\end{abstract}

Ключевые слова: сульфид свинца, химическое осаждение, легирование кобальтом, морфология пленок, структурные свойства, ширина запрещенной зоны, вольтовая и токовая фоточувствительность.

DOI: $10.21883 /$ FTP.2021.11.51560.9706

\section{1. Введение}

Тонкие пленки $\mathrm{PbS}$ широко используются в оптоэлектронике и сенсорике в качестве материалов ИК-детекторов, оптических переключателей, эффективных устройств преобразования солнечного излучения, химических сенсоров, датчиков температуры и открытого пламени [1-8].

Эффективным инструментом изменения полупроводниковых и фотоэлектрических свойств слоев $\mathrm{PbS}$ является их легирование путем введения в реакционную смесь в процессе химического осаждения добавок солей металлов. Такой прием обеспечивает возможность получения высокофункциональных пленок в одну технологическую стадию, исключая дополнительный процесс сенсибилизации.

Во многих публикациях [9-14] при легировании сульфида свинца катионами $\mathrm{Li}^{+}, \mathrm{Cu}^{2+}, \mathrm{Ca}^{2+}, \mathrm{Sr}^{2+}, \mathrm{Ga}^{2+}$, $\mathrm{Fe}^{2+}$ увеличение ширины запрещенной зоны, повышение коэффициента преобразования солнечного излучения и фотопроводимости слоев объясняется, в частности, уменьшением размеров кристаллитов в слое.
Результаты наших предыдущих исследований [15-17] показали, что вводимые допанты активно влияют непосредственно на сам процесс химического осаждения пленок. Так, введение анионосодержащей компоненты соли в виде галогенидов $\left(\mathrm{NH}_{4} \mathrm{Cl}, \mathrm{NH}_{4} \mathrm{Br}, \mathrm{NH}_{4} \mathrm{I}\right)$ либо катионов щелочных металлов (лития, натрия, калия) изменяет кинетику осаждения $\mathrm{PbS}$, увеличивая индукционный период и снижая скорость образования сульфидной фазы. При этом изменяются кристаллическая структура, размер и форма зерен, формирующих слои сульфида свинца, что приводит к сенсибилизации пленок к излучению в ближнем ИК-диапазоне спектра и повышению фотоответа. Так, натурные испытания фоторезисторов на основе легированных галогенами пленок $\mathrm{PbS}$ показали их высокие пороговые характеристики (вольт-ваттную чувствительность, обнаружительную способность, постоянную времени) в диапазоне $333-393 \mathrm{~K}$, что демонстрирует широкие перспективы практического использования в качестве быстродействующих пожарных извещателей пламени [4].

Увеличению индукционного периода образования твердой фазы $\mathrm{PbS}$ способствует также введение в ре- 
акционную смесь хлоридов щелочноземельных металлов $(\mathrm{Ca}, \mathrm{Sr}$ и $\mathrm{Ba})[18,19]$. Проведенные комплексные исследования синтезированных пленок, легированных этими элементами, свидетельствуют об эволюции их морфологических и структурных характеристик (параметра решетки, микродеформаций, степени текстурированности) и, следовательно, влияют на их оптические и фоточувствительные свойства.

В свою очередь, сравнительный термодинамический анализ эффективных произведений растворимости $\mathrm{PbS}$ и сульфидов меди(II) или галлия демонстрирует подтвержденное экспериментально увеличение скорости зарождения твердой фазы путем образования первичных центров зародышеобразования за счет сульфидной фазы металлов-допантов, имеющих более низкие значения произведения растворимости по сравнению с $\mathrm{PbS}$ [20]. Проведенные в работе [20] измерения фотоэлектрических характеристик пленок сульфида свинца, осажденных в присутствии солей $\mathrm{Cu}^{2+}$ и $\mathrm{Ga}^{3+}$, свидетельствуют о трех-четырехкратном снижении их вольт-ваттной чувствительности к ближнему ИК-излучению по сравнению со слоями, синтез которых проходил при введении солей магния, кальция и кадмия, замедляющих процесс образования сульфидной фазы.

В работе [21] установлено влияние концентрации $\mathrm{FeCl}_{2}$ в реакционной смеси на полупроводниковые свойства $\mathrm{PbS}$, в частности, на ширину запрещенной зоны пленок $\mathrm{PbS}: \mathrm{Fe}$, а также на интенсивность примесных полос поглощения из-за изменений в зонной структуре при нахождении ионов железа в междоузлиях и в позиции $\mathrm{Pb}^{2+}$ в кристаллической решетке сульфида свинца. Скорость роста примесных полос поглощения в оптических спектрах пленок $\mathrm{PbS}: \mathrm{Fe}$ позволила предположить, что фотопроводимость обусловлена в основном носителями заряда, создаваемыми ионами железа [22].

Резюмируя вышеизложенное, можно сделать вывод о том, что введение легирующих примесей в полупроводниковые слои $\mathrm{PbS}$, реализуемое в процессе их химического осаждения, является достаточно эффективным приемом модификации свойств. Практическая значимость и открывающиеся перспективы легирования пленок сульфида свинца стимулируют поиск и исследование новых допантов для придания пленкам одного из наиболее востребованных узкозонных полупроводников практически важных фотоэлектрических и электрофизических свойств.

В настоящей работе, являющейся продолжением исследований по легированию пленок сульфида свинца при химическом осаждении, рассмотрено влияние на их морфологию, структурные, электрофизические и фотоэлектрические свойства ионов кобальта.

\section{2. Методика эксперимента}

Тонкопленочные слои сульфида свинца синтезировали химическим осаждением из водных растворов, содержащих 0.04 моль/л ацетата свинца $\mathrm{Pb}\left(\mathrm{CH}_{3} \mathrm{COO}\right)_{2}$, 0.3 моль/л цитрата натрия $\mathrm{Na}_{3} \mathrm{C}_{6} \mathrm{H}_{5} \mathrm{O}_{7}, 4.0$ моль/л гидроксида аммония $\mathrm{NH}_{4} \mathrm{OH}, 0.15$ моль/л $\mathrm{NH}_{4} \mathrm{I}$ и 0.58 моль/л тиомочевины $\left(\mathrm{NH}_{2}\right)_{2} \mathrm{CS}$. Легирование пленок $\mathrm{PbS}$ кобальтом $\mathrm{Co}^{2+}$ в процессе химического осаждения осуществляли путем дополнительного введения в реактор от 0.012 до 0.12 моль/л соли $\mathrm{CoCl}_{2}$ при их осаждении в течение 1.5 ч и от 0.08 до 0.16 моль/л при 3-часовом процессе синтеза. Все пленки осаждали на предварительно обезжиренные подложки из стекла в жидкостном термостате „ТС-ТБ-10“при $353 \mathrm{~K}$, обеспечивающем точность поддержания температуры $\pm 0.1 \mathrm{~K}$. Для слоев сульфида свинца, осажденных из реакционной смеси без введения солей допантов, использовали обозначение $\mathrm{PbS}$, осажденных в присутствии иодида аммония $\mathrm{PbS}(\mathrm{I})$, хлорида кобальта (II) PbS (Co), иодида аммония и хлорида кобальта $\mathrm{PbS}$ (I, Co).

Толщину полученных пленок определяли с помощью интерференционного микроскопа (микроинтерферометра Линника) МИИ-4М с погрешностью измерения 20\%.

Микроструктуру и элементный анализ пленок изучали с использованием растровых электронных микроскопов MIRA 3 LMU (при ускоряющем напряжении электронного пучка 10 кВ) и JEOL JSM-5900 LV с энергодисперсионным рентгеновским анализатором EDS Inca Energy 250.

Рентгеновские исследования осажденных пленок проводили в интервале углов $2 \theta$ от 20 до $100^{\circ}$ с шагом $0.01^{\circ}$ и скоростью съемки 0.5 об/мин на дифрактометре Rigaku MiniFlex600 (Rigaku, Япония). Для уточнения структурных параметров синтезированных пленок использовали метод полнопрофильного анализа Ритвелда $[23,24]$ с применением программы Fullprof [25]. Для разделения вкладов размера зерен и деформации в изучаемых пленках в ширину дифракционных отражений использовали уравнение Уильямсона-Холла (conventional Williamson-Hall plot) [26]:

$$
\beta \cdot \cos \theta=0.9 \lambda / D+4 \varepsilon \cdot \sin \theta,
$$

где $D-$ средний размер областей когерентного рассеяния, принимаемый за средний размер частиц, $\beta-$ полуширина рефлекса в радианах, $\lambda$ - длина волны используемого рентгеновского излучения, $\varepsilon=\Delta d / d-$ деформация, $d$ - межплоскостное расстояние.

Оптические исследования пленок проводили в ближнем ИК-диапазоне в интервале $0.2<E<1.4$ эВ при $300 \mathrm{~K}$ с использованием призменного спектрометра. Спектры поглощения $\alpha(E)$ рассчитывали из экспериментально полученных спектров пропускания $t(E)$ без учета отражения по формуле

$$
\alpha(E)=\frac{1}{d_{f}} \ln \left(\frac{1}{t(E)}\right),
$$

где $d_{f}$ - толщина пленки, $t(E)=I / I_{0}-$ пропускание пленки, $I, I_{0}-$ интенсивность света, прошедшего через пленку и через подложку соответственно. 
Фотоэлектрические характеристики (темновое сопротивление $R_{d}$, вольтовую чувствительность $U_{s}$ ) пленок $\mathrm{PbS}(\mathrm{I}, \mathrm{Cr})$ измеряли на установке К.54.410 с источником излучения АЧТ $573 \mathrm{~K}$ при частоте модуляции излучения 800 Гц и облученности $1 \cdot 10^{-4} \mathrm{BT} / \mathrm{cm}^{2}$.

Вольт-амперные характеристики (BAX) пленок $\mathrm{PbS}$, $\mathrm{PbS}(\mathrm{I}), \operatorname{PbS}(\mathrm{Co})$ и $\mathrm{PbS}(\mathrm{I}, \mathrm{Co})$ регистрировали при температуре $298 \mathrm{~K}$ в диапазоне приложенного напряжения от -10 до 10 В с шагом 100 мВ двухзондовым методом как в темноте, так и при освещенности $100 \mathrm{MBT} / \mathrm{cm}^{2}$ пучком света от симулятора солнечного излучения Zolix GLORIA-X500A, оборудованного лампой Osram XBO 500W/H OFR. Величину силы тока определяли источником-измерителем Keithley 2450.

Определение типа проводимости осажденных пленок $\mathrm{PbS}(\mathrm{I}), \mathrm{PbS}(\mathrm{Co}), \mathrm{PbS}(\mathrm{I}, \mathrm{Co})$ осуществляли по знаку термоэдс при создании градиента температур в области зондовых контактов.

\section{3. Результаты и их обсуждение}

\section{1. Исследование морфологии}

Химическим осаждением при варьировании концентрации соли $\mathrm{CoCl}_{2}$ от 0.001 до 0.16 моль/л при фиксированных концентрациях остальных компонентов в цитратно-аммиачной реакционной ванне получены пленки $\mathrm{PbS}(\mathrm{I}, \mathrm{Co})$ серого цвета с хорошей адгезией к стеклянной подложке. Концентрационные зависимости толщины пленок $\mathrm{PbS}(\mathrm{I}, \mathrm{Co})$, полученных при длительности процесса 1.5 и 3 ч, показаны на рис. 1.

Характер обсуждаемых зависимостей существенно различается. При химическом осаждении в течение 1.5 ч повышение содержания соли хлорида кобальта в реакторе до 0.02 моль/л приводит к резкому снижению толщины полупроводникового слоя от 475 и до 370 нм. Дальнейшее повышение концентрации соли кобальта в реакторе до 0.12 моль/л обеспечивает увеличение толщины слоя до $\sim 430$ нм. При более длительном синтезе (3 ч) в интервале концентраций 0.04-0.12 моль/л $\mathrm{CoCl}_{2}$ толщина сформированной пленки практически не меняется, составляя $\sim 470$ нм. Дальнейшее повышение содержания соли кобальта до 0.16 моль/л сопровождается снижением толщины слоя до $400 \mathrm{Hм}$, что связано с перераспределением сульфидной фазы в объем реактора вследствие ускорения процесса химического осаждения в этих условиях из-за более интенсивного зародышеобразования.

Микроструктуру пленок $\mathrm{PbS}(\mathrm{I})$ и $\mathrm{PbS}(\mathrm{I}, \mathrm{Co})$ в виде электронно-микроскопических изображений и гистограммы распределения в них частиц по размерам иллюстрирует рис. 2. Повышение содержания $\mathrm{CoCl}_{2}$ в реакторе в пределах 0.008-0.016 моль/л при длительности осаждения 1.5 ч и в концентрационном диапазоне 0.08-0.12 моль/л при 3-часовом синтезе заметно отражается на морфологии и размере зерен.
При этом пленка сульфида свинца, легированная только иодом $\mathrm{PbS}(\mathrm{I})$, представляет собой достаточно однородную микроструктуру со средним размером зерен 150-200 нм ( 70\%) и единичными глобулами диаметром до $\sim 1$ мкм с содержанием до $\sim 18 \%$ наноразмерных частиц. Проанализируем влияние на процесс содержания хлорида кобальта в реакционной ванне, а также длительности процесса химического осаждения. Видно, что при осаждении в течение 1.5 ч повышение концентрации $\mathrm{CoCl}_{2}$ в реакторе способствует формированию частиц в достаточно широком размерном интервале - 100-400 нм, доля которых возрастает от 75 (0.008 моль/л) до 95\% (0.016 моль/л). Увеличение длительности процесса до 3 ч сопровождается практически в том же концентрационном диапазоне повышением однородности частиц $\mathrm{PbS}(\mathrm{I}, \mathrm{Co})$. Диапазон их размеров сужается до 100-250 нм (75-78\%). При этом доля частиц размером до 100 нм увеличивается при осаждении в течение 1.5 ч от $1-8$ до $13-28 \%$ при 3-часовом синтезе.

Таким образом, видно, что в результате введения в реакционную ванну хлорида кобальта (II) происходит формирование более однородной микроструктуры пленки $\mathrm{PbS}(\mathrm{I}, \mathrm{Co})$, сопровождающееся увеличением содержания в ней наночастиц.

Исследование элементного состава обсуждаемых пленок по всей площади поверхности пленки проводили на содержание основных химических элементов (Pb, Co, $\mathrm{S}, \mathrm{I})$ с использованием энергодисперсионного анализа. Элементный анализ легированного иодом слоя $\mathrm{PbS}(\mathrm{I})$ свидетельствует о том, что как отдельные глобулы, так и поверхность состоят преимущественно из свинца и серы, содержание которых в среднем по десяти измерениям составило 49.8 и 48.3 ат\% соответственно, а содержание иода $\sim 1.9$ ат\% (табл. 1). Полученные результаты свидетельствуют о некоторой нестехиометрии химического состава синтезированных пленок $\mathrm{PbS}(\mathrm{I})$ : соотно-

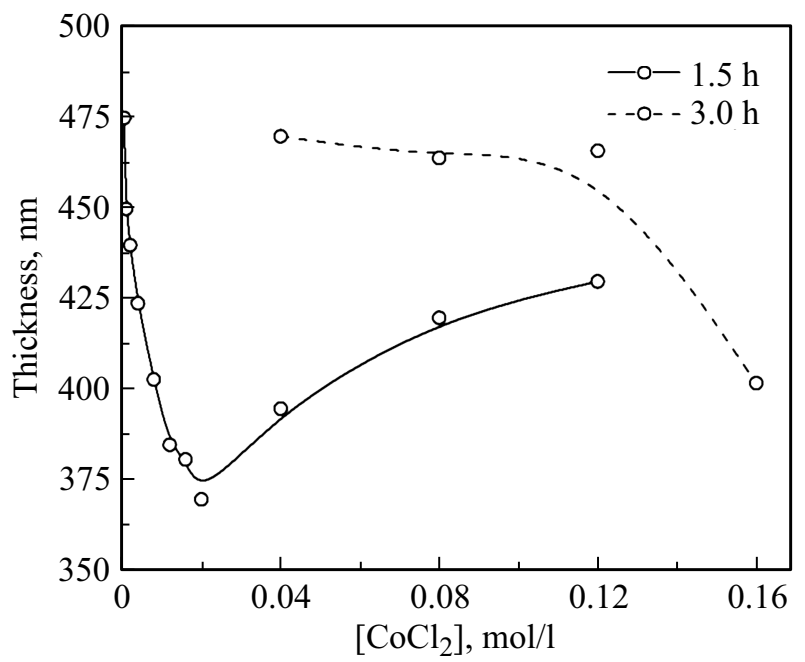

Рис. 1. Зависимость толщины пленок $\mathrm{PbS}(\mathrm{I}, \mathrm{Co})$ от концентрации $\mathrm{CoCl}_{2}$ в реакционной ванне при длительности химического осаждения 1.5 и 3 ч. 

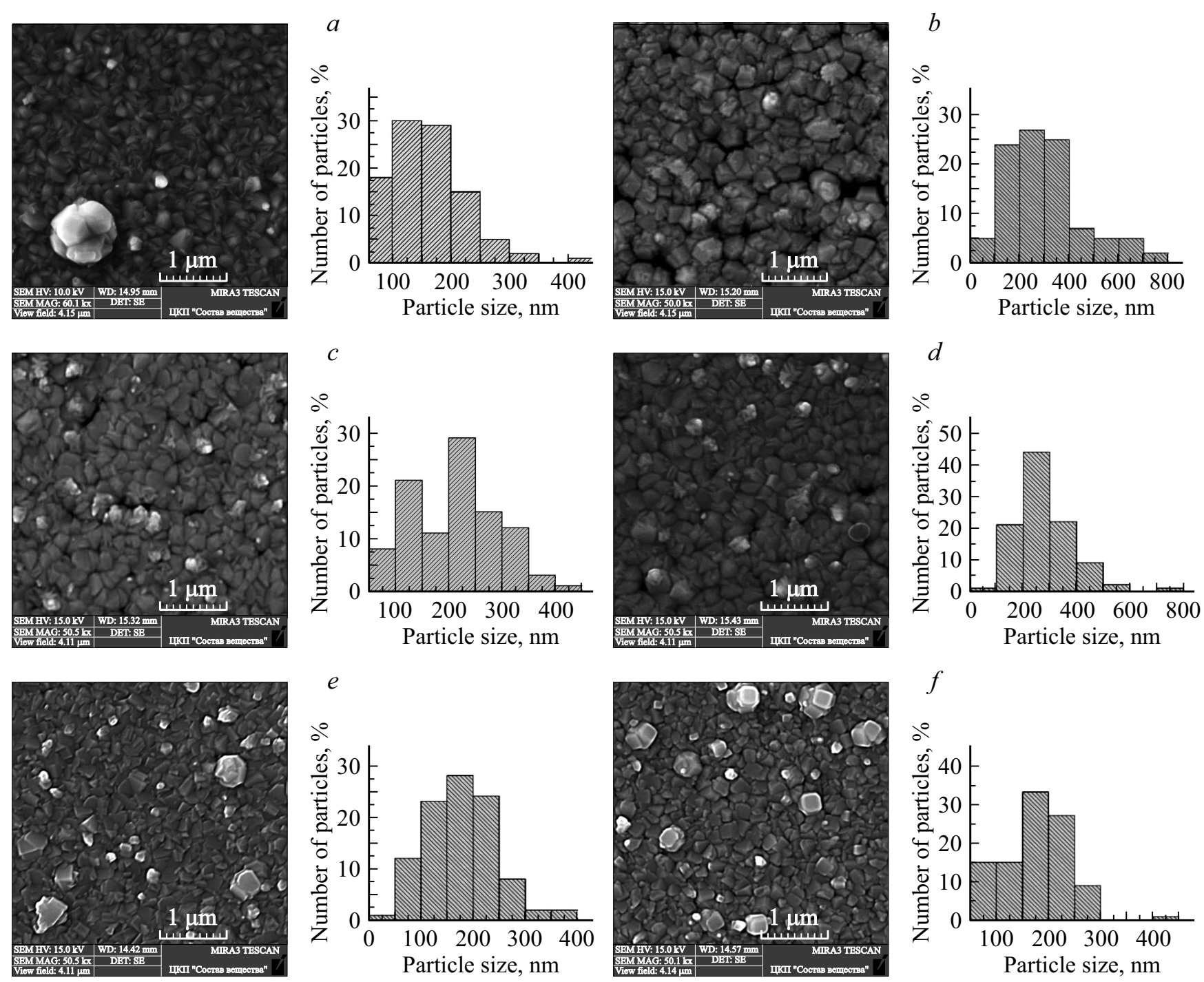

Рис. 2. Электронно-микроскопические изображения пленок $\mathrm{PbS}(\mathrm{I})(a), \mathrm{PbS}(\mathrm{I}, \mathrm{Co})$, осажденных из реакционной ванны, содержащей, моль/л: $0.008(b), 0.012(c), 0.016(d), 0.08(e), 0.12(f)$, и гистограммы распределения в них частиц по размерам. Пленки $(a-d)$ и $(e, f)$ получены химическим осаждением в течение 1.5 и 3 ч соответственно.

шение металла к халькогену составило 1.03 , что может быть связано с образованием в пленке иодсодержащих соединений металла или дефектностью кристаллической структуры.

Энергодисперсионный элементный микроанализ показал, что в слоях, легированных одновременно иодом и кобальтом $\mathrm{PbS}(\mathrm{I}, \mathrm{Co})$, повышение в реакторе концентрации $\mathrm{CoCl}_{2}$ с 0.008 до 0.040 моль/л приводит к уменьшению содержания свинца с 48.37 до 46.35 ат\% с одновременным повышением содержания серы от 49.46 до 52.86 ат\% и снижением содержания иода с 2.17 до $0.7 \mathrm{aT \%}$. (табл. 1). Причем только в одной точке из 10 при концентрации 0.04 моль/л $\mathrm{CoCl}_{2}$ обнаружено 0.87 ат\% кобальта при среднем его содержании 0.09 ат\%. Введение в реактор меньших концентраций соли либо не обеспечивает вхождение кобальта в пленку, либо пе- реходный металл не обнаруживается вследствие слабой чувствительности EDX анализа.

При осаждении пленок в течение 1.5 ч по мере повышения соли кобальта $\mathrm{CoCl}_{2}$ (с 0.008 до 0.04 моль/л)

Таблица 1. Элементный состав пленок $\mathrm{PbS}(\mathrm{I})$ и $\mathrm{PbS}(\mathrm{I}, \mathrm{Co})$

\begin{tabular}{c|c|c|c|c|c|c|c}
\hline \multirow{2}{*}{ Элемент, ат\% } & \multicolumn{7}{|c}{$\left[\mathrm{CoCl}_{2}\right]$, моль/л } \\
\cline { 2 - 8 } & 0 & 0.008 & 0.012 & 0.016 & 0.040 & $0.08^{*}$ & $0.12^{*}$ \\
\hline $\mathrm{Pb}$ & 49.8 & 48.37 & 48.29 & 48.06 & 46.35 & 47.17 & 47.3 \\
$\mathrm{~S}$ & 48.3 & 49.46 & 49.76 & 50.20 & 52.86 & 51.83 & 51.52 \\
$\mathrm{I}$ & 1.9 & 2.17 & 1.95 & 1.74 & 0.7 & 0.90 & 1.1 \\
$\mathrm{Co}$ & - & - & - & - & 0.09 & 0.1 & 0.08 \\
$(\mathrm{~Pb}+\mathrm{Co}) / \mathrm{S}$ & 1.03 & 0.98 & 0.97 & 0.96 & 0.88 & 0.91 & 0.92
\end{tabular}

Примечание. * Длительность химического осаждения пленок $\operatorname{PbS}(\mathrm{I}, \mathrm{Co})-3$ ч. 

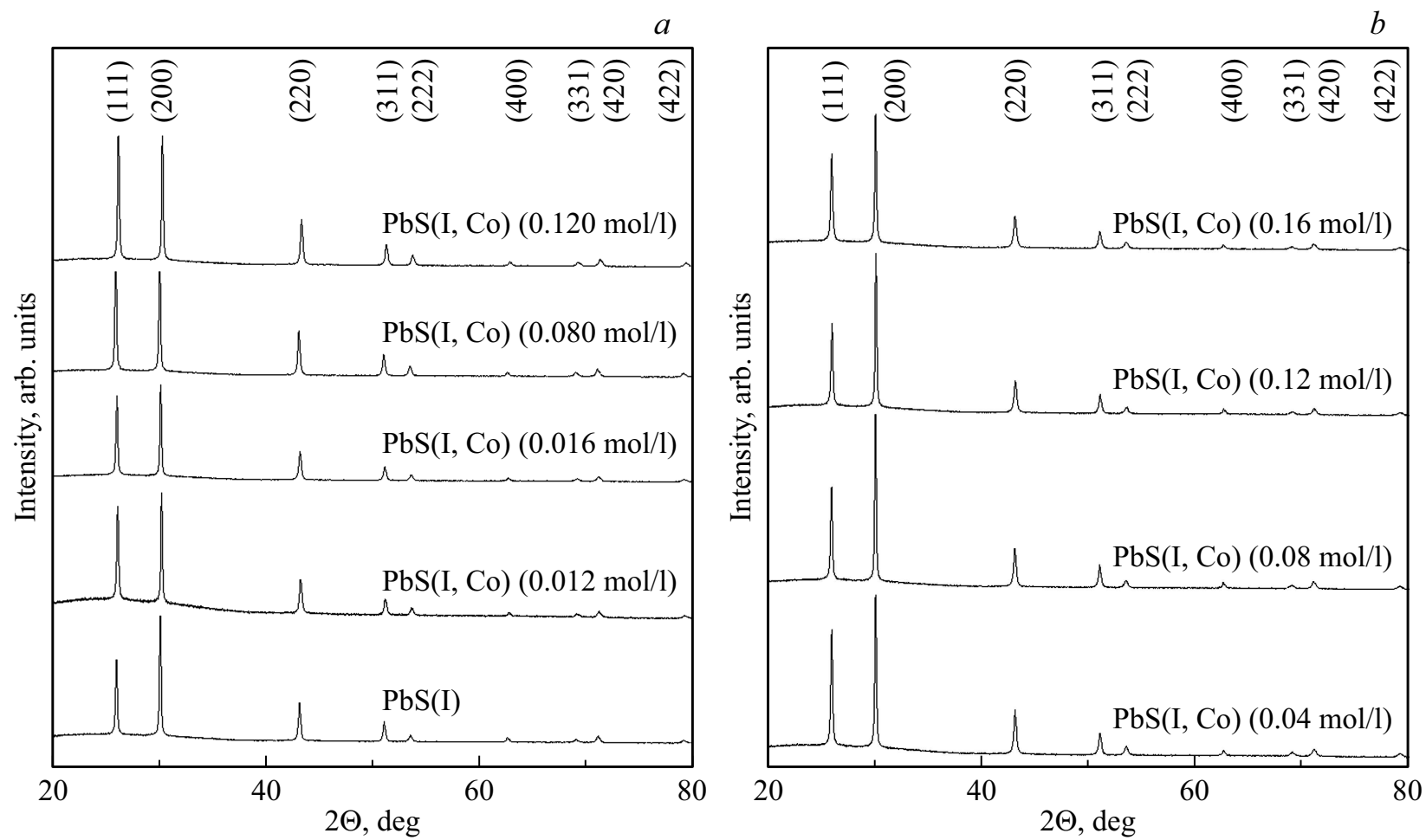

Рис. 3. Рентгенограммы пленок $\operatorname{PbS}(\mathrm{I})$ и $\mathrm{PbS}(\mathrm{I}, \mathrm{Co})$, осажденных в течение $1.5(a)$ и 3 ч $(b)$ из реакционной ванны с различным содержанием $\mathrm{CoCl}_{2}$.

соотношение $(\mathrm{Pb}+\mathrm{Co}) / \mathrm{S}$ постепенно уменьшается с 0.98 до 0.88. В свою очередь при проведении 3-часового осаждения в присутствии фиксированной концентрации иодида аммония и хлорида кобальта $(0.08$ и 0.12 моль/л) содержание металла-допанта в слое несколько увеличивается по сравнению с менее длительным процессом синтеза. При этом соотношение суммы металлов с халькогеном $(\mathrm{Pb}+\mathrm{Co}) / \mathrm{S}$ находится в пределах 0.91-0.92.

Оценивая результаты элементного анализа, необходимо заметить, что среднее содержание кобальта обнаруженное в пленках $\mathrm{PbS}(\mathrm{I}, \mathrm{Co})$, синтезированных из реакционных ванн с концентрацией 0.080 и 0.12 моль/л $\mathrm{CoCl}_{2}$, составило соответственно 0.1 и 0.08 ат\%. При этом легированные кобальтом пленки $\mathrm{PbS}(\mathrm{I}, \mathrm{Co})$ по результатам оценки их типа проводимости обладали проводимостью $p$-типа в отличие от нелегированной пленки $\mathrm{PbS}$. Аналогичный эффект был обнаружен нами ранее в пленках $\mathrm{PbS}$, легированных кальцием [18] и железом (II) [21].

\section{2. Кристаллическая структура}

Для идентификации структурных различий осаждаемых в присутствии хлорида кобальта пленок $\mathrm{PbS}$ нами был использован метод рентгенофазового анализа. На рис. 3 приведены рентгенограммы пленок сульфида свинца, легированных только иодом $\mathrm{PbS}(\mathrm{I})$ и одновременно иодом и кобальтом $\mathrm{PbS}(\mathrm{I}, \mathrm{Co})$ в процессе химиче- ского осаждения в течение 1.5 (рис. $3, a)$ и 3 ч (рис. $3, b$ ) на подложки из стекла.

Спектр рентгеновской дифракции пленок $\mathrm{PbS}(\mathrm{I})$ и $\mathrm{PbS}(\mathrm{I}, \mathrm{Co})$ содержит набор дифракционных отражений, характерных кубической гранецентрированной структуpe $B 1$ (пр.гр. $F m \overline{3} m$ ). Изотропный фон рентгенограмм с достаточно небольшой шириной рефлексов и отсутствие диффузного гало позволяет констатировать, что исследуемые легированные слои являются поликристаллическими и однофазными.

Уточненные параметры кристаллической решетки пленок $\mathrm{PbS}(\mathrm{I}, \mathrm{Co})$ с использованием полнопрофильного анализа Ритвелда, адаптированного к компьютерной программе FullProf, приведены в табл. 2. Для большинства тонкопленочных слоев параметры кристаллической решетки пленок $\mathrm{PbS}(\mathrm{I}, \mathrm{Co})$ меньше периода элементарной ячейки слоя $\mathrm{PbS}$, легированного иодом $\left(a_{B 1}=0.59377(6)\right.$ нм $)$. Исключение представляют пленки $\mathrm{PbS}(\mathrm{I}, \mathrm{Co})$, синтезированные в течение 1.5 ч из реакционных ванн с содержанием $0.012\left(a_{B 1}=0.59408(1) \mathrm{Hм}\right)$ и 0.020 моль/л $\left(a_{B 1}=0.59451(4) \mathrm{HM}\right) \mathrm{CoCl}_{2}$ при фиксированных концентрациях остальных компонентов.

Известно, что радиус иона кобальта $\mathrm{Co}^{2+}(0.072 \mathrm{Hм})$ значительно меньше радиуса иона свинца $\mathrm{Pb}^{2+}$ $(0.119$ нм). Можно было бы предположить определенную вероятность замещения „хозяина“ кристаллической решетки металлом-допантом с образованием твердого раствора $\mathrm{Co}_{x} \mathrm{~Pb}_{1-x} \mathrm{~S}$, связанное с уменьшением периода 
Таблица 2. Параметр решетки $a_{B 1}$, количество зерен с преимущественной ориентацией $(111)_{B 1}$ и $(200)_{B 1}$, параллельной плоскости подложки $T_{(111)}$ и $T_{(200)}$, среднее значение микродеформаций в кристаллической решетке $\Delta d / d(\Delta d-$ отклонение от среднего значения межплоскостного расстояния $d$ ) и размер областей когерентного рассеяния $\mathrm{OKP}(D)$ пленок $\mathrm{PbS}(\mathrm{I})$ и $\mathrm{PbS}(\mathrm{I}, \mathrm{Co})$

\begin{tabular}{|c|c|c|c|c|c|}
\hline$\left[\mathrm{CoCl}_{2}\right]$, моль/л & $a, \mathrm{HM}$ & $\Delta d / d \cdot 10^{4}$ & $T_{(200)}, \%$ & $T_{(111)}, \%$ & $D, \mathrm{Hм}$ \\
\hline \multicolumn{6}{|c|}{ Синтез 1.5 ч } \\
\hline $\begin{array}{c}0 \\
0.012 \\
0.016 \\
0.020 \\
0.040 \\
0.080 \\
0.120\end{array}$ & $\begin{array}{l}0.59377(6) \\
0.59408(1) \\
0.59368(8) \\
0.59451(4) \\
0.59339(8) \\
0.59358(5) \\
0.59352(6)\end{array}$ & $\begin{array}{r}25 \pm 5 \\
22.1 \pm 4 \\
24.3 \pm 5 \\
34.1 \pm 6 \\
19.2 \pm 4 \\
21.3 \pm 4 \\
23.1 \pm 5\end{array}$ & $\begin{aligned} 29.2 & \pm 0.3 \\
9.4 & \pm 0.1 \\
16.2 & \pm 0.2 \\
16.1 & \pm 0.2 \\
0.4 & \pm 0.04 \\
7.0 & \pm 0.1 \\
& -\end{aligned}$ & $\begin{array}{c}- \\
- \\
- \\
- \\
- \\
- \\
16.4\end{array}$ & $\begin{array}{l}495 \pm 20 \\
227 \pm 10 \\
330 \pm 15 \\
235 \pm 10 \\
478 \pm 20 \\
462 \pm 20 \\
420 \pm 20\end{array}$ \\
\hline \multicolumn{6}{|c|}{ Синтез 3 ч } \\
\hline $\begin{array}{l}0.04 \\
0.08 \\
0.12 \\
0.16\end{array}$ & $\begin{array}{l}0.593506(7) \\
0.593569(7) \\
0.593611(8) \\
0.593603(8)\end{array}$ & $\begin{array}{l}26.4 \pm 4 \\
23.4 \pm 4 \\
16.7 \pm 3 \\
29.8 \pm 5\end{array}$ & $\begin{array}{l}22.4 \pm 0.2 \\
27.9 \pm 0.3 \\
33.0 \pm 0.3 \\
22.9 \pm 0.2\end{array}$ & $\begin{array}{l}- \\
- \\
- \\
-\end{array}$ & $\begin{array}{l}408 \pm 20 \\
231 \pm 10 \\
217 \pm 10 \\
396 \pm 20\end{array}$ \\
\hline
\end{tabular}

кристаллической решетки. Однако рентгеноструктурные исследования не дают однозначного ответа об образовании твердого раствора замещения, поскольку содержание присутствующих в тонкопленочных слоях легирующих примесей кобальта и иода изменяется одновременно (табл. 1). Установленные параметры кристаллической решетки синтезированных соединений $\mathrm{PbS}(\mathrm{I}, \mathrm{Co})$ свидетельствуют лишь о структурной модификации полупроводниковых слоев. Имеющее место превышение периода кристаллической решетки по сравнению с $\mathrm{PbS}(\mathrm{I})$ можно объяснить внедрением ионов $\mathrm{Co}^{2+}$ в междоузлия с одновременным возникновением вакансий в подрешетке свинца.

Кроме того, проведенный полнопрофильный анализ рентгенограмм показал различное соотношение интенсивностей дифракционных отражений $(111)_{B 1}$ и $(200)_{B 1}$ в синтезированных пленках, что обусловлено разной преимущественной кристаллографической ориентацией в них зерен. В пленке нелегированного кобальтом сульфида свинца $\mathrm{PbS}(\mathrm{I})$ 29.2\% кристаллитов, из которых она сформирована, ориентированы плоскостью $(200)_{B 1}$, т.е. параллельно плоскости подложки, а остальные хаотично расположены на поверхности. После легирования кобальтом тонкопленочного слоя $\mathrm{PbS}(\mathrm{I})$ уменьшается доля кристаллитов, растущих плоскостью $(200)_{\text {в } 1}$ до $0.4-16.2 \%$, с синхронным повышением хаотически расположенных агрегатов в структуре пленки. Однако при максимальной концентрации соли кобальта $(0.12$ моль/л) в реакторе и такой же длительности осаждения (1.5 ч) наблюдается переориентация кристаллитов и рост их плоско-

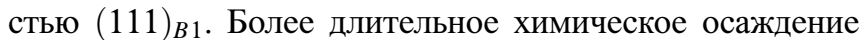
и введение кобальта до $0.08-0.10$ ат\% способствует увеличению доли кристаллитов, растущих плоскостью
$(200)_{B 1}$ до 22.4-33.0\%, упорядочивая кристаллическую структуру тонкопленочного покрытия сульфида свинца.

Как известно, основными причинами уширения рефлексов являются малый размер зерен $D$ (точнее области когерентного рассеяния ОКР) и микронапряжения в объеме материала. Разделение их вклада, выполненное методом Уильямсона-Холла, показано на вставке рис. 4. Для примера приведен анализ рентгенограммы пленки $\mathrm{PbS}(\mathrm{I}, \mathrm{Co})$, осажденной в течение 1.5 ч из реакционной ванны с содержанием 0.04 моль/л $\mathrm{CoCl}_{2}$, а на вставке зависимость физического уширения от угла в виде

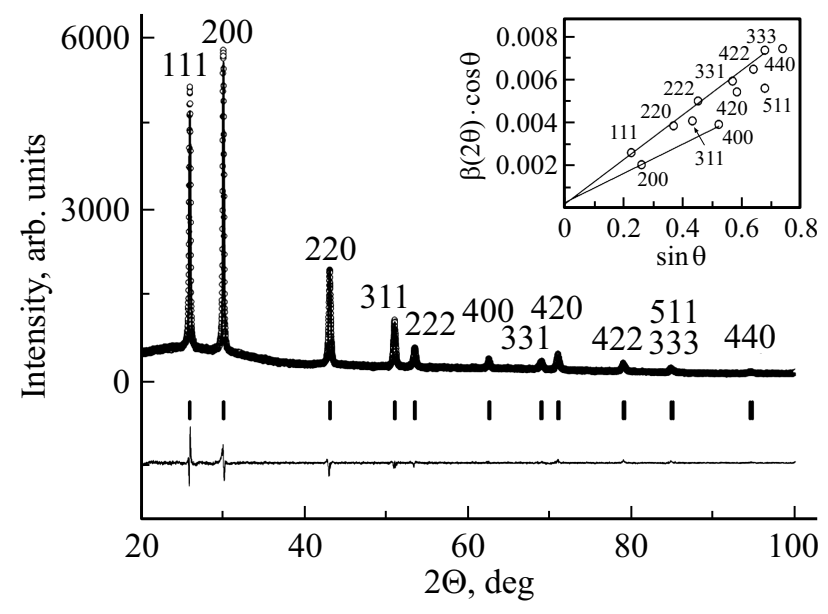

Рис. 4. Рентгенограмма пленки $\mathrm{PbS}(\mathrm{I}, \mathrm{Co})$, осажденной в течение 1.5 ч из реакционной ванны с содержанием 0.04 моль/л $\mathrm{CoCl}_{2}$. Нижняя линия - разница между расчетными и экспериментальными картинами рентгеноструктурного анализа. Штрихами обозначены угловые положения пиков фазы $B 1$. На вставке представлена зависимость $\beta(2 \theta) \cos \theta$ от $\sin \theta$. 
$\beta(2 \theta) \cos \theta$ от $\sin \theta$. Подобные процедуры применены к анализу всех дифракционных спектров.

Наклон этих зависимостей указывает на наличие деформаций в объеме пленки, а отсекаемый отрезок на оси ординат $(\sin \theta=0)$ дает их размер $D$. Наблюдаются значительные отклонения экспериментальных точек от линейной зависимости $\beta(2 \theta) \cos \theta$ от $\sin \theta$, указывающие на существование деформационной анизотропии в слоях $\mathrm{PbS}(\mathrm{I}, \mathrm{Co})$, обусловленной возникновением дислокаций. Микродеформации $\Delta d / d$ в кристаллической решетке слоя $\mathrm{PbS}(\mathrm{I})$ после легирования кобальтом снижаются до $(19.2-24.3) \cdot 10^{-4}$. Исключение представляет пленка $\mathrm{PbS}(\mathrm{I}, \mathrm{Co})$, в которой их величина достигает $34.1 \cdot 10^{-4}$, что в обоих случаях приводит к искажению кристаллической решетки. Размер зерен $(D)$, из которых сформированы обсуждаемые пленки, вначале растет от 227 до 478 нм, затем снижается до 420 нм. При 3-часовом осаждении пленок наблюдается немонотонная зависимость размеров зерна от концентрации $\mathrm{CoCl}_{2}$, но размеры их ниже, чем у слоя, легированного только иодом $(495 \pm 20$ нм), а микронапряжения, возникающие в них, составляют $(16.7-29.8) \cdot 10^{-4}$. Отметим, что размеры областей когерентного рассеивания (ОКР), полученные из рентгеновских исследований, удовлетворительно согласуются со средними размерами частиц, определенными с помощью растровой микроскопии.

Модификация полупроводникового слоя $\mathrm{PbS}(\mathrm{I})$ путем его легирования кобальтом приводит к значительным изменениям фундаментальных свойств исследуемого материала. В соответствии с принципами синергетики неравновесные условия, в которых осуществляется химическое осаждение обсуждаемых тонкопленочных слоев $\mathrm{PbS}(\mathrm{I}, \mathrm{Co})$, ведут к образованию в них неоднородностей вследствие процессов самоорганизации. Изменения на уровне морфологии, в частности присутствие точечных включений кобальта, а также образование мелких частиц на поверхности зерен (рис. 2, $c, d$ ) либо неравномерное распределение более крупных кристаллитов (рис. 2, $e, f$ ) на поверхности подложки приводят к возникновению микронапряжений в объеме материала. Это сопровождается созданием уровней локализованных состояний в запрещенной зоне и, как следствие, изменением свойств, связанных с электронной подсистемой, т. е. оптических и фоточувствительных.

\section{3. Оптические свойства}

Значительный интерес представляло выяснение влияния концентрации соли кобальта и длительности процесса химического осаждения пленок $\mathrm{PbS}(\mathrm{I}, \mathrm{Co})$ на оптические свойства обсуждаемых полупроводниковых соединений.

На рис. 5, a показаны спектры поглощения пленок $\mathrm{PbS}(\mathrm{I}, \mathrm{Co})$, осажденных в течение 1.5 ч из реакционных ванн, содержащих 0.012, 0.016 и 0.04 моль/л $\mathrm{CoCl}_{2}$, а на рис. 6, $a$ приведены спектры поглощения пленок $\mathrm{PbS}(\mathrm{I}, \mathrm{Co})$, химическое осаждение которых длилось 3 ч в присутствии 0.08 и 0.12 моль/л хлорида кобальта.
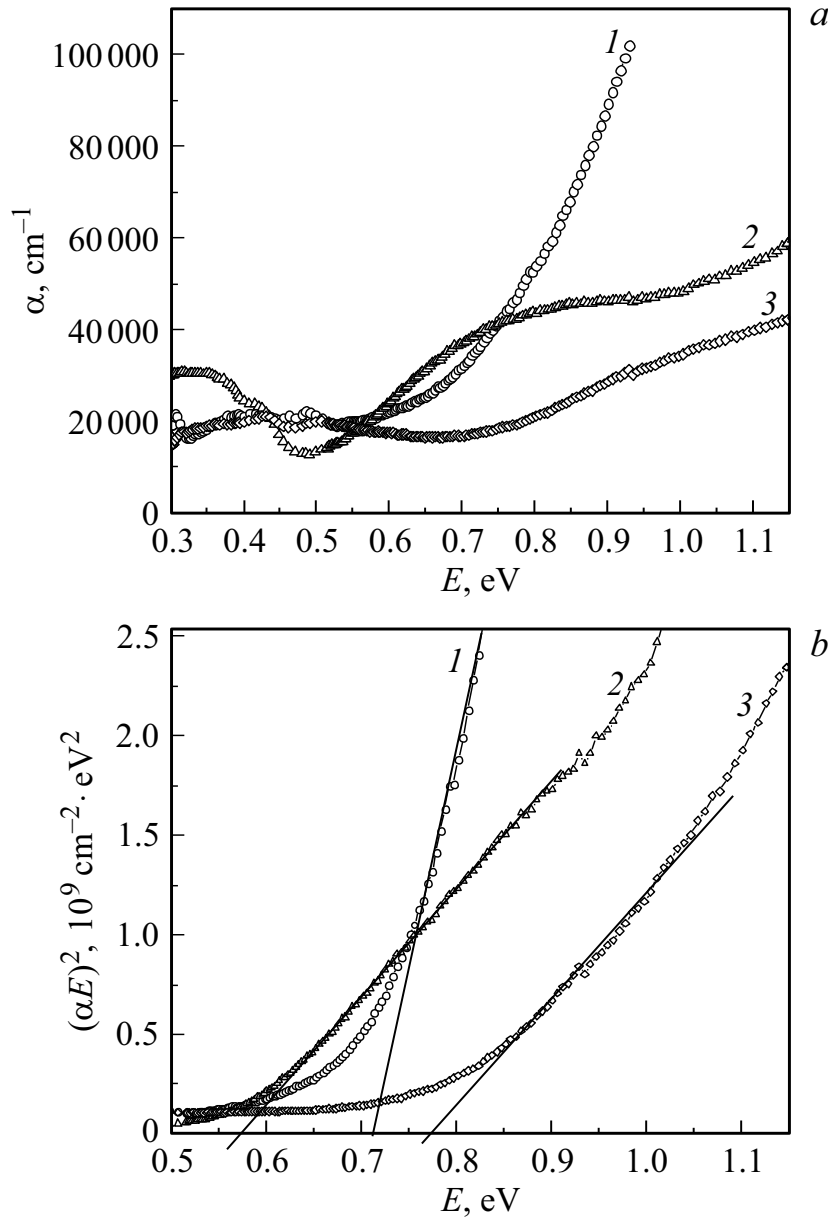

Рис. 5. Спектры поглощения пленок $\mathrm{PbS}(\mathrm{I}, \mathrm{Co})$, синтезированных в течение 1.5 ч из реакционных ванн, содержащих 0.012 (1), 0.016 (2) и 0.04 моль/л (3) $\mathrm{CoCl}_{2}$ (a), и спектры поглощения тех же пленок, построенные в координатах $(\alpha E)^{2} \sim E(b)$.

Зависимость интенсивности полосы поглощения при 0.35 эВ от содержания соли кобальта в реакторе носит немонотонный характер: наибольшая интенсивность наблюдается для пленки, осажденной из ванны, содержащей 0.016 моль/л (1.5 ч) хлорида кобальта. Уменьшение интенсивности этой полосы для пленок, осажденных при добавке 0.012 и 0.04 моль/л $\mathrm{CoCl}_{2}$, коррелирует с увеличением в них доли наночастиц до 4 и $\sim 8 \%$ соответственно. Для сравнения, в слое, полученном при 0.016 моль/л $\mathrm{CoCl}_{2}$, доля нанофазы составляет всего $1 \%$. Корреляция также касается уменьшения параметра решетки, текстурированности и микронапряжений в синтезированных пленках.

Для определения ширины запрещенной зоны $E_{g}$ полученных пленок $\mathrm{PbS}(\mathrm{I}, \mathrm{Co})$ спектры поглощения были построены в координатах $(\alpha E)^{2} \sim E$ (рис. 5, $b$ и 6,b). Экстраполяция линейного участка на ось абсцисс позволяет определить величину $E_{g}$. С увеличением доли наночастиц в пленках $\mathrm{PbS}(\mathrm{I}, \mathrm{Co}) 1,4$ и $8 \%$ при осаждении в течение 1.5 ч в присутствии $0.016,0.012$ 

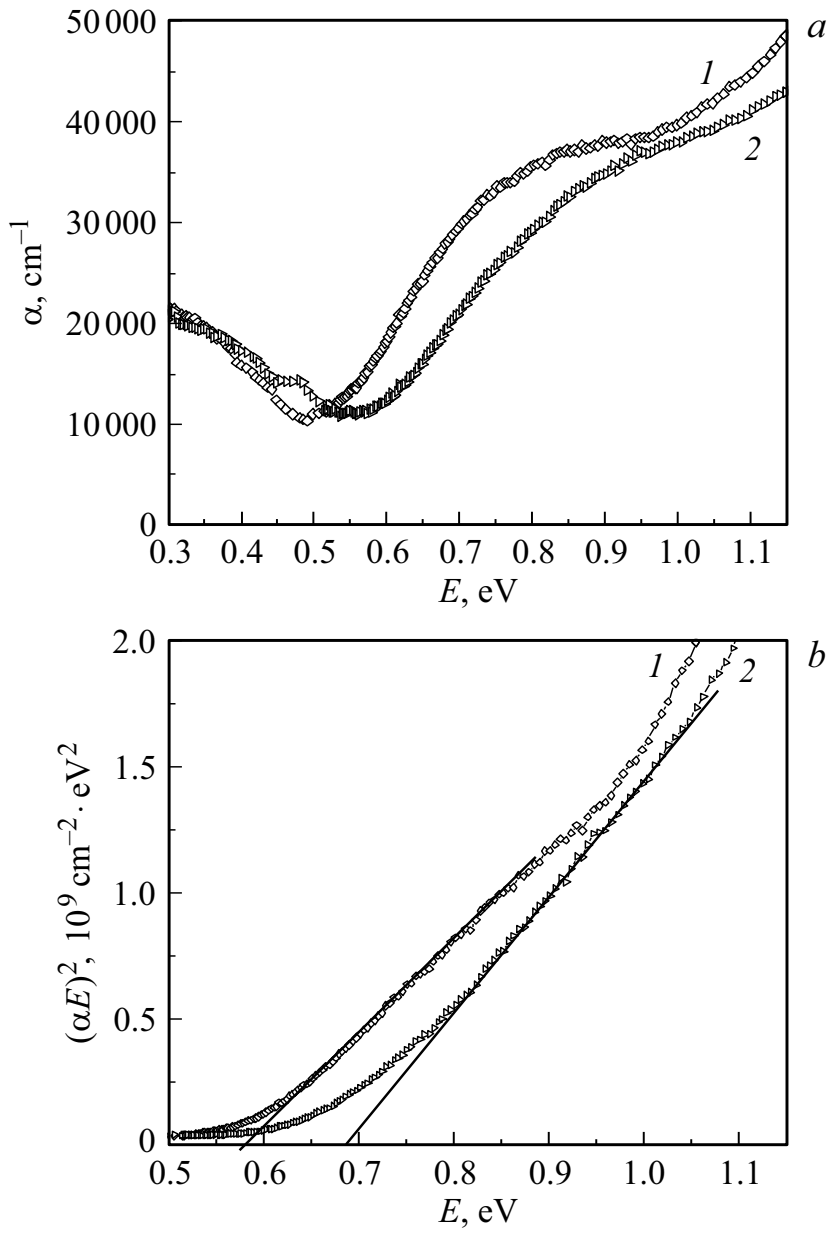

Рис. 6. Спектры поглощения пленок $\mathrm{PbS}(\mathrm{I}, \mathrm{Co})$, синтезированных в течение 3 ч из реакционных ванн, содержащих 0.08 (1), 0.12 моль/л (2) $\mathrm{CoCl}_{2}$ (a), и спектры поглощения тех же пленок, построенные в координатах $(\alpha E)^{2} \sim E(b)$.

и 0.04 моль/л хлорида кобальта $E_{g}$ увеличивается до 0.57 , 0.68 и 0.75 эВ соответственно. Аналогичная тенденция наблюдается и при 3-часовом химическом осаждении из реакционной ванны, содержащей 0.08 и 0.12 моль/л $\mathrm{CoCl}_{2}$. Доля наночастиц в пленках $\mathrm{PbS}(\mathrm{I}, \mathrm{Co})$ повышается при этом от 13 до $\sim 28 \%$, что сопровождается также ростом ширины запрещенной зоны до 0.57 и 0.68 эВ. В последнем случае полученное значение ширины запрещенной зоны, несмотря на сравнительно большее содержание частиц нанодиапазона, обусловлено значительным изменением морфологии тонкопленочного слоя за счет вторичного зародышеобразования, наблюдаемого, в частности, на рис. $2, e$ и $f$.

\section{4. Электрофизические свойства}

Путем изменения размеров зерен, их ориентации и легирования можно изменять фотоэлектрические свойства тонкопленочного $\mathrm{PbS}$. Известно, что вольтовая чувствительность $U_{S}$ и темновое сопротивление $R_{d}$ поликристаллических тонкопленочных соединений прояв- ляют высокую восприимчивость даже к тысячным или сотым долям процента присутствия примесей, меняя тип проводимости полупроводника. Как было установлено нами ранее $[18,19]$, при легировании пленок $\mathrm{PbS}$ иодом установлена инверсия типа проводимости от электронного к дырочному $(n \rightarrow p)$. Все пленки, полученные в присутствии хлорида кобальта (II) и иодида аммония $\mathrm{PbS}(\mathrm{I}, \mathrm{Co})$, обладают $p$-типом проводимости.

Динамика изменения фотоэлектрических свойств элементов $(5 \times 5) \mathrm{Mм}^{2}$ на основе слоев $\mathrm{PbS}(\mathrm{I}, \mathrm{Co})$ от содержания хлорида кобальта (II) в реакционной ванне показана на рис. 7. На зависимости вольтовой чувствительности $U_{s}$ как функции концентрации хлорида кобальта $\mathrm{CoCl}_{2}$ в реакционной ванне пленок $\mathrm{PbS}(\mathrm{I}, \mathrm{Co})$, химическое осаждение которых длилось 1.5 ч, наблюдаются два максимума 250 мкВ (0.016 моль/л) и 120 мкВ (0.08 моль/л). Экстремумы соответствуют минимальному содержанию наночастиц, т.е. 1 и 4\%, а темновое сопротивление составляет 1.5 и $0.8 \mathrm{MOM} \mathrm{на} \mathrm{квадрат}$ соответственно.

После 3-часового осаждения слои $\mathrm{PbS}(\mathrm{I}, \mathrm{Co})$, толщина которых превышает 1.5-часовые пленки примерно
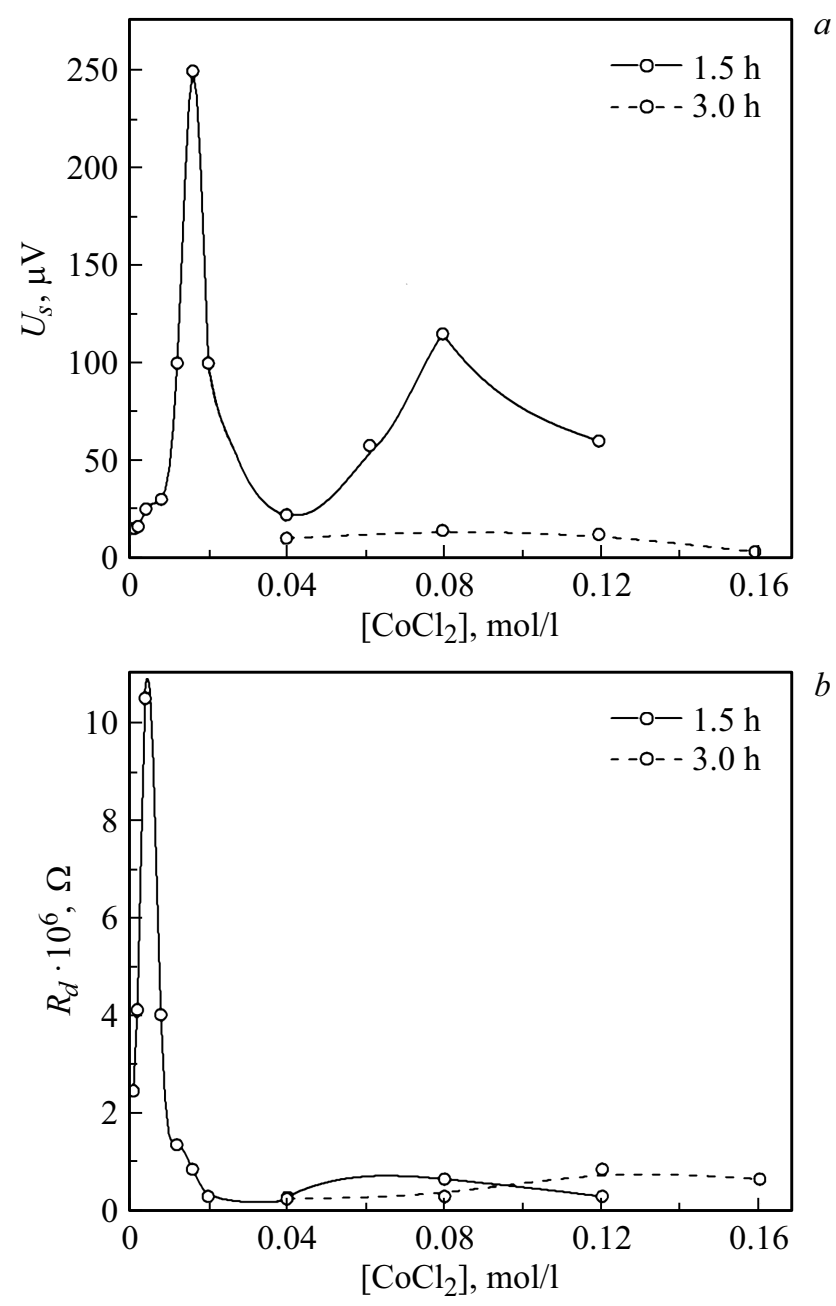

Рис. 7. Изменение вольтовой чувствительности $U_{S}(a)$ и темнового сопротивления $R_{d}(b)$ элементов $(5 \times 5)$ мм $^{2}$ на основе пленок $\mathrm{PbS}(\mathrm{I}, \mathrm{Co})$ от концентрации $\mathrm{CoCl}_{2}$ в реакционной ванне. 
на $\sim 50-100$ нм, обладают более слабым фотоответом. Их вольтовая фоточувствительность не превышает 30 мкВ при темновом сопротивлении $R_{d} \leq 0.8 \mathrm{MOм} \mathrm{на}$ квадрат. Отметим, что количество наночастиц в этих пленках составляет $\sim 13-28 \%$ от общего числа.

Анализ приведенных результатов по фотоэлектрическим свойствам пленок $\mathrm{PbS}(\mathrm{I}, \mathrm{Co})$ показывает существенное влияние размеров кристаллитов, формирующих слой, оценка которых проведена в работе с помощью растровой электронной микроскопии. Сопоставление фоточувствительных свойств пленок $\mathrm{PbS}(\mathrm{I}, \mathrm{Co})$ с их микроструктурой (рис. 2) позволяет сделать вывод о том, что уменьшение содержания наночастиц в слое сопровождается ростом вольтовой чувствительности слоев при легировании их кобальтом в процессе синтеза. Выявленная зависимость не согласуется с выдвинутой ранее $[27,28]$ гипотезой повышения фоточувствительности полупроводниковых пленок сульфида свинца по барьерному механизму.

Одной из причин уменьшения фотоответа при возрастании доли частиц наномасштабного диапазона может быть снижение концентрации носителей, участвующих в фотопроводимости, при увеличении удельной поверхности осаждаемых пленок вследствие интенсификации процесса их рекомендации на адсорбированных межзеренными границами примесях.

Световые вольт-амперные характеристики тонкопленочных слоев $\mathrm{PbS}(\mathrm{Co}), \mathrm{PbS}, \mathrm{PbS}(\mathrm{I}, \mathrm{Co})$ и $\mathrm{PbS}(\mathrm{I})$ демонстрируют линейную зависимость выходного тока, генерируемого при освещении элемента $(5 \times 5) \mathrm{MM}^{2}$, от падения напряжения на этой нагрузке (см. вставку на рис. 8). Фототок определяется размерами кристаллитов, которые можно изменять, проводя легирование пленок сульфида свинца кобальтом $\mathrm{PbS}(\mathrm{Co})$ либо одновременно кобальтом и иодом $\mathrm{PbS}(\mathrm{I}, \mathrm{Co})$, либо иодом $\mathrm{PbS}(\mathrm{I})$. На рис. 8 приведена зависимость плотности фототока от количества наночастиц, входящих в состав пленок, с их микроизображениями, свидетельствующими об изменении морфологии.

Необходимо отметить, что в пленках $\operatorname{PbS}(\mathrm{Co})$ и $\mathrm{PbS}$ наночастицы практически отсутствуют, в то же время при освещении первой пленки плотность тока составила 265.5, а второй фактически вдвое меньше 121.5 мкА/см². Эффект повышения фототока в пленках сульфида свинца, обнаруженный при легировании донорной примесью в виде хрома (III) [29] и кобальта (II) [30], объясняется тем, что оба переходных элемента усиливают взаимодействие пленки $\mathrm{PbS}$ с падающим светом, сопровождающееся генерацией фотоносителей внутри системы путем возбуждения электронов и их переходом в зону проводимости. Предположения, высказанные в этой публикации, позволяют объяснить максимальную плотность фототока в слое $\mathrm{PbS}(\mathrm{Co})$, содержащем кобальт по сравнению с нелегированной пленкой $\mathrm{PbS}$. В свою очередь, возникновение слабого фототока в поверхностных слоях $\mathrm{PbS}(\mathrm{I}, \mathrm{Co})$ и $\mathrm{PbS}(\mathrm{I})$ связано, в первую очередь, с влиянием акцепторной примеси иода, приводящей к снижению концентрации носителей в зоне проводимости исследуемых полупроводниковых матери-

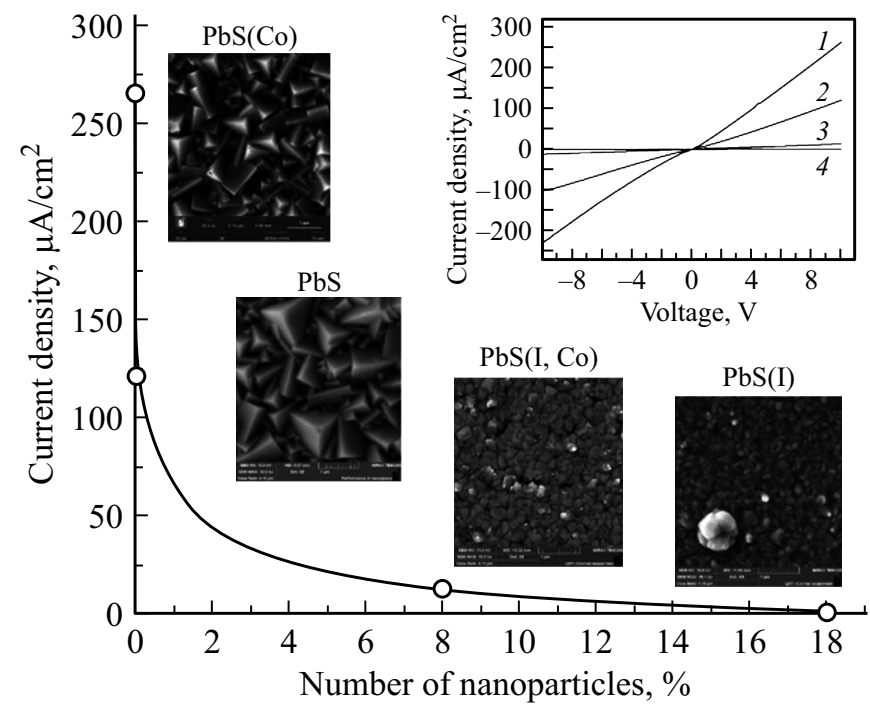

Рис. 8. Зависимость плотности фототока от количества наночастиц в слое и микроизображения пленок $\mathrm{PbS}(\mathrm{Co}), \mathrm{PbS}$, $\mathrm{PbS}(\mathrm{I}, \mathrm{Co}) \mathrm{PbS}(\mathrm{I})$. На вставке - вольт-амперные характеристики пленок $\mathrm{PbS}(\mathrm{Co})(1), \mathrm{PbS}(2), \mathrm{PbS}(\mathrm{I}, \mathrm{Co})$ (3) $\mathrm{PbS}(\mathrm{I})$ (4).

алов. Стоит обратить внимание и на тот факт, что в $\mathrm{PbS}(\mathrm{I}, \mathrm{Co})$ и $\mathrm{PbS}(\mathrm{I})$ содержится соответственно 8 и $18 \%$ наночастиц.

Таким образом, плотность фототока снижается в ряду $\mathrm{PbS}(\mathrm{Co}) \rightarrow \mathrm{PbS} \rightarrow \mathrm{PbS}(\mathrm{I}, \mathrm{Co}) \rightarrow \mathrm{PbS}(\mathrm{I})$, повторяя идентичную зависимость снижения вольтовой чувствительности с увеличением содержания нанофазы в обсуждаемых слоях.

\section{4. Заключение}

Исследовано влияние содержания $\mathrm{CoCl}_{2}$ в реакционной ванне на морфологию, гранулометрический и элементный состав пленок $\mathrm{PbS}(\mathrm{I}, \mathrm{Co})$. При этом, по данным элементного анализа, включение кобальта имеет локальный характер и сопровождается снижением содержания иода с 2.17 до 0.7 ат\%, а также соотношения между суммой металлов и халькогеном от 0.98 до 0.88. Повышение концентрации хлорида кобальта в реакторе способствует формированию более однородной микроструктуры слоя $\mathrm{PbS}(\mathrm{I}, \mathrm{Co})$ и росту количества наночастиц до $\sim 28 \%$.

Рентгеноструктурные исследования пленок $\mathrm{PbS}(\mathrm{I}, \mathrm{Co})$ свидетельствуют о сохранении кубической гранецентрированной структуры $B 1$ (пр. гр. $F m \overline{3} m)$ и их структурной модификации.

Установлена корреляция между шириной запрещенной зоны и количеством частиц нанометрого диапазона, зависящего от морфологии синтезированных пленок. Показано, что с увеличением содержания нанодисперсий в пленках $\mathrm{PbS}(\mathrm{Co}), \mathrm{PbS}, \mathrm{PbS}(\mathrm{I}, \mathrm{Co})$ и $\mathrm{PbS}(\mathrm{I})$ происходит снижение вольтовой и токовой чувствительности к излучению ближнего ИК-диапазона вследствие интенсификации процесса рекомбинации носителей на примесных атомах, адсорбированных межзеренными границами. 


\section{Финансирование работы}

Работа выполнена при финансовой поддержке программы 211 Правительства Российской Федерации № 02.А03.21.0006, грантов РФФИ 20-48-660041p_а и 18-29-11051мк в рамках государственного задания Министерства образования и науки (тема „Поток“ № AАAА-A18-118020190112-8 и „Спин“ № АAААA18-118020290104-2).

\section{Конфликт интересов}

Авторы заявляют, что у них нет конфликта интересов.

\section{Список литературы}

[1] S. Kouissa, A. Djemel, M.S. Aida, M A. Djouadi. Sensors \& Transducers, 193, 106 (2015).

[2] V.F. Markov, L.N. Maskaeva. J. Anal. Chem., 56 (8), 754 (2001).

[3] I.V. Zarubin, V.F. Markov, L.N. Maskaeva, N.V. Zarubina, M.V. Kuznetsov. J. Anal. Chem., 72 (3), 266 (2017).

[4] В.Ф. Марков, Л.Н. Маскаева, А.В. Шнайдер, Р.Х. Сарыева. Техносферная безопасность, 1 (6), 32 (2015).

[5] A.N. Chattarki, S.S. Kamble, L.P. Deshmukh. Mater. Lett., 67 (1), 39 (2012).

[6] L.F. Koao, F.B. Dejene, H.C. Swart. Int. J. Electrochem. Sci., 9, 1747 (2014)

[7] K.C. Preetha, K. Deepa, A.C. Dhanya, T.L. Remadevi. IOP Conf. Ser. Mater. Sci. Eng., 73 (1), 012086 (2015).

[8] B.A. Ezekoye, T.M. Emeakaroha, V.A. Ezekoye, K.O. Ighodalo. Int. J. Phys. Sci., 10 (13), 385 (2015).

[9] M. Portillo, X. Chavez, H. Mathew. Superlatt. Microstr., 109, 423 (2017).

[10] R. Li, W. Li, M. Liu, Q. He, Y. Wang, Q. Zhan, T. Wang. ES Mater. Manuf., 4, 38 (2019).

[11] E. Yücel, Y. Yücel. Optik - Int. J. for Light and Electron Optics, 142, 82 (2017).

[12] E. Yücel, Y. Yücel. Ceramics Int., 43 (1), 407 (2017).

[13] Reshmi Radhakrishnana, Hiba Rahmana, S. Dhanyaa, R. Geethua, Nafsia Karima, K. Faseelaa, P.V. Sreenivasanb, B. Pradeepc, Rachel Reena Philipa. AIP Conf. Proc., 1391, 755 (2011).

[14] O. Portillo Moreno, R. Gutierrez Perez, M. Chavez Portillo, L. Chaltel Lima, G. Hernández Téllez, E. Rubio Rosas. Optic, 127 (22), 10273 (2016).

[15] В.Ф. Марков, Л.Н. Маскаева, Г.А. Китаев. ЖПХ, 73, 1256 (2000).

[16] В.Ф. Марков, А.В. Шнайдер, М.П. Миронов, В.Ф. Дьяков, Л.Н. Маскаева. Перспективные матер., 3, 28 (2008).

[17] Т.А. Алексеева, В.Ф. Марков, Л.Н. Маскаева, Н.А. Третьякова, В.И. Воронин. Бутлеровские сообщения, 17 (6), 13 (2009).

[18] Л.Н. Маскаева, Е.В. Мостовщикова, В.Ф. Марков, В.И. Воронин. ФТП, 53 (2), 174 (2019).

[19] Л.Н. Маскаева, Е.В. Мостовщикова, В.И. Воронин, Е.Э. Лекомцева, П.С. Богатова, В.Ф. Марков. ФТП, 54 (10), 1041 (2020).

[20] Л.Н. Маскаева, Н.А. Форостяная, В.Ф. Марков, А.С. Еремина, К.А. Карпов. Бутлеровские сообщения, 51 (7), 115 (2017).
[21] Л.Н. Маскаева, И.В. Ваганова, Е.В. Мостовщикова, В.И. Воронин, Н.А. Чуфарова, А.Д. Кутявина. ЖФХ, 94 (12), 1783 (2020).

[22] E.V. Mostovshchikova, V.I. Voronin, L.N. Maskaeva, I.V. Vaganova, N.A. Chufarova, V.P. Glazkov. J. Anal. Chem., 852, 15693 (2021).

[23] H.M. Rietveld. J. Appl. Crystallogr., 2 (2), 65 (1969).

[24] D.L. Bush, J.E. Post. Rev. Mineralogy, 20, 369 (1990).

[25] J. Rodriges-Carvajal. Physica B, 192, 55 (1993).

[26] G.K. Williamson, W.H. Hall. Acta Metall, 1, 22 (1953).

[27] Л.Н. Неустроев, В.В. Осипов. Микроэлектроника, 17 (5), 399 (1988).

[28] В.И. Петров, В.А. Прохоров, А.Э. Юнович. ФТП, 18 (3), 484 (1984).

[29] M. Ahmed, M. Rabia, M. Shaban. RSC Adv., 10, 14458 (2020).

[30] Arzu Ekinci, Ömer Şahin, Sabit Horoz. J. Mater. Sci.: Mater. Electron., 31, 1210 (2020).

Редактор А.Н. Смирнов

\section{Cobalt-doped chemically precipitated lead sulfide films}

L.N. Maskaeva ${ }^{\mathbf{1 , 2}}$, E.V. Mostovshchikova ${ }^{3}$, V.F. Markov ${ }^{1,2}$, V.I. Voronin ${ }^{3}$, A.V. Pozdin ${ }^{1}$, I.O. Selyanin ${ }^{4}$, A.I Mikhailova ${ }^{1}$

${ }^{1}$ Ural Federal University named after the First President of Russia B.N. Yeltsin, 620002 Yekaterinburg, Russia

${ }^{2}$ Ural Institute of State Fire Service,

Emergency Ministry of Russia, 620062 Yekaterinburg, Russia

${ }^{3}$ M.N. Mikheev Institute of Metal Physics, Ural Branch, Russian Academy of Sciences, 620108 Yekaterinburg, Russia

${ }^{4}$ Institute of Solid State Chemistry of the Ural Branch of the Russian Academy of Sciences,

620108 Yekaterinburg, Russia

Abstract This work is a continuation of studies on the doping of chemically deposited $\mathrm{PbS}(\mathrm{I})$ layers and discusses the effect of cobalt ions on films' morphological, structural, optical, and photoelectric properties. Elemental energy-dispersive analysis showed that cobalt was detected in films at the $\geq 0.04 \mathrm{~mol} / 1$ $\mathrm{CoCl}_{2}$ concentration in the reaction mixture. The produced $\mathrm{PbS}(\mathrm{I}, \mathrm{Co})$ films retain the $B 1$ cubic structure (space group). An established trend of the $\mathrm{PbS}(\mathrm{I}, \mathrm{Co})$ films band gap increase from 0.57 to $0.75 \mathrm{eV}$ is connected with an increase in the content of nanoparticles in them from 1 to $\sim 8 \%$ for deposition during $1.5 \mathrm{~h}$. For a 3 -hour process, we also observed a bandgap increase from 0.57 to $0.68 \mathrm{eV}$ corresponding to the fraction rise of nanoparticles - from 13 to $\sim 28 \%$. The concentration dependence of the $\mathrm{PbS}(\mathrm{I}, \mathrm{Co})$ films volt sensitivity deposited for $1.5 \mathrm{~h}$ exhibits two maxima corresponding to 1 and $4 \%$ nanoparticle contents. During a three-hour synthesis process, a sharp photoresponse decrease was noted with an increase in the content of nanoscale particles to $\sim 13-28 \%$ in the $\mathrm{PbS}(\mathrm{I}, \mathrm{Co})$ layers. We showed that the photocurrent density decreases with an increase in the content of nanoparticles in the films in the series $\mathrm{PbS}(\mathrm{Co}) \rightarrow \mathrm{PbS} \rightarrow \mathrm{PbS}(\mathrm{I}, \mathrm{Co}) \rightarrow \mathrm{PbS}(\mathrm{I})$. 